\title{
The EMIF-AD PreclinAD study: study design and baseline cohort overview
}

\author{
Elles Konijnenberg ${ }^{1 *}$ D , Stephen F. Carter ${ }^{2}$, Mara ten Kate ${ }^{1}$, Anouk den Braber ${ }^{1,3}$, Jori Tomassen ${ }^{1}$, Chinenye Amadi ${ }^{2}$, \\ Linda Wesselman ${ }^{1}$, Hoang-Ton Nguyen ${ }^{4}$, Jacoba A. van de Kreeke ${ }^{4}$, Maqsood Yaqub ${ }^{5}$, Matteo Demuru', \\ Sandra D. Mulder ${ }^{6}$, Arjan Hillebrand ${ }^{7}$, Femke H. Bouwman ${ }^{1}$, Charlotte E. Teunissen ${ }^{6}$, Erik H. Serné ${ }^{8}$, \\ Annette C. Moll', Frank D. Verbraak ${ }^{4}$, Rainer Hinz ${ }^{9}$, Neil Pendleton ${ }^{2}$, Adriaan A. Lammertsma ${ }^{5}$, \\ Bart N. M. van Berckel ${ }^{5}$, Frederik Barkhof ${ }^{5,10}$, Dorret I. Boomsma ${ }^{3}$, Philip Scheltens ${ }^{1}$, Karl Herholz ${ }^{2}$ \\ and Pieter Jelle Visser ${ }^{1,11}$
}

\begin{abstract}
Background: Amyloid pathology is the pathological hallmark in Alzheimer's disease (AD) and can precede clinical dementia by decades. So far it remains unclear how amyloid pathology leads to cognitive impairment and dementia. To design AD prevention trials it is key to include cognitively normal subjects at high risk for amyloid pathology and to find predictors of cognitive decline in these subjects. These goals can be accomplished by targeting twins, with additional benefits to identify genetic and environmental pathways for amyloid pathology, other AD biomarkers, and cognitive decline.

Methods: From December 2014 to October 2017 we enrolled cognitively normal participants aged 60 years and older from the ongoing Manchester and Newcastle Age and Cognitive Performance Research Cohort and the Netherlands Twins Register. In Manchester we included single individuals, and in Amsterdam monozygotic twin pairs. At baseline, participants completed neuropsychological tests and questionnaires, and underwent physical examination, blood sampling, ultrasound of the carotid arteries, structural and resting state functional brain magnetic resonance imaging, and dynamic amyloid positron emission tomography (PET) scanning with $\left[{ }^{18} \mathrm{~F}\right] f$ lutemetamol. In addition, the twin cohort underwent lumbar puncture for cerebrospinal fluid collection, buccal cell collection, magnetoencephalography, optical coherence tomography, and retinal imaging.
\end{abstract}

Results: We included 285 participants, who were on average $74.8 \pm 9.7$ years old, 64\% female. Fifty-eight participants (22\%) had an abnormal amyloid PET scan.

Conclusions: A rich baseline dataset of cognitively normal elderly individuals has been established to estimate risk factors and biomarkers for amyloid pathology and future cognitive decline.

Keywords: Preclinical Alzheimer's disease, Amyloid, Cognitively normal, Monozygotic twins, $\left[{ }^{18} \mathrm{~F}\right]$ flutemetamol

\section{Background}

Alzheimer's disease (AD) is the most common cause of dementia and is characterized by amyloid plaques and neurofibrillary tangles with subsequently progressive neuronal loss and eventually death [1]. Aggregation of amyloid is supposed to be the first event in $\mathrm{AD}$ and starts years before cognitive impairment occurs [2-4].

\footnotetext{
* Correspondence: e.konijnenberg@vumc.nl

${ }^{1}$ Alzheimer Center, Department of Neurology, VU University Medical Center, Neuroscience Amsterdam, PO Box 7057, 1007 MB Amsterdam, The Netherlands Full list of author information is available at the end of the article
}

Postmortem pathological and biomarker studies have demonstrated that $20-40 \%$ of cognitively normal elderly individuals possess abnormal amyloid levels in their brain [4-9]. These subjects are considered to be in the preclinical stage of $\mathrm{AD}[10,11]$. This presymptomatic window provides a unique opportunity for secondary prevention studies, as subjects have limited brain damage and no symptoms yet. Understanding the pathophysiological mechanisms underlying amyloid pathology in this preclinical stage of $\mathrm{AD}$ might also be critical to

(c) The Author(s). 2018 Open Access This article is distributed under the terms of the Creative Commons Attribution 4.0 International License (http://creativecommons.org/licenses/by/4.0/), which permits unrestricted use, distribution, and 
identify possible drug targets for the development of effective treatments.

There are, however, several research challenges for the development of prevention strategies in the preclinical AD stage. First, amyloid markers are needed for the diagnosis of preclinical AD. There is an urgent need for readily applicable screening markers, such as blood or imaging markers, to identify cognitively normal subjects at increased risk for amyloid pathology so that more expensive or invasive tests such as positron emission tomography (PET) scan or cerebrospinal fluid (CSF) via lumbar puncture can be performed in more selected populations. A number of markers have already been identified for this purpose but these need to be validated in preclinical/prodromal stages of the disease [12-15]. Second, there is still an incomplete understanding of what drives the development of amyloid pathology in cognitively normal subjects. Previous studies have identified a limited number of risk factors for amyloid pathology, such as Apolipoprotein E (APOE) genotype, age, and level of education [4, 16-18]. These established risk factors, however, can only explain part of the risk for amyloid pathology. Third, amyloid pathology has been associated with an increased risk for cognitive decline, but the rate of decline varies greatly [19]. A few possible prognostic factors in preclinical AD have been identified but they await replication [20, 21]. Fourth, current normative data for biomarkers and cognitive markers may be suboptimal as many cognitively normal subjects already have amyloid pathology. Finally, CSF and PET biomarkers for amyloid pathology do not match in about $15 \%$ of cases [22-24], in particular in cognitively normal subjects. It has been suggested that amyloid changes can be detected earlier in CSF than by PET but this requires further investigation [25].

In this paper, we describe the study design of the multisite PreclinAD study, which aims to address these clinical research challenges. Within this study, cognitively normal elderly individuals are recruited from the Manchester and Newcastle Age and Cognitive Performance Research Cohort (ACPRC) in Manchester [26] and the Netherlands Twin Register (NTR) in Amsterdam [27]. From the NTR we recruited monozygotic (MZ) twins. When a relation is observed between two markers, studying $M Z$ twins enables exploring the nature of the observed relation: the MZ twin differences approach gives the possibility to study the relation excluding confounding by genetic factors (the twins are genetically identical); and the cross-twin cross-trait design, studying whether marker 1 in one twin can predict marker 2 in their co-twin, gives the opportunity to study the contribution of shared familial factors (genes and common environment) to the relation. Previous studies using AD-type dementia as an outcome estimated the amount of variance explained by genetic factors to be around $80 \%$ [28], suggesting a major genetic role in the development of AD. However, there is a lack of studies estimating the contribution of genetic and environmental influences on AD biomarkers in nondemented individuals and the role of environmental risk and protective factors for $\mathrm{AD}$ remains unclear [18].

The PreclinAD study aimed to: validate existing and discover new markers for amyloid pathology in cognitively normal elderly individuals; identify risk factors for amyloid pathology; identify prognostic markers for cognitive decline in cognitively normal subjects with amyloid pathology (Fig. 1); and determine the contribution of genetic and environmental influences on these markers.

\section{Methods}

\section{Project}

The European Medical Information Framework for $A D$

The study is part of the Innovative Medicine Initiative European Medical Information Framework for AD

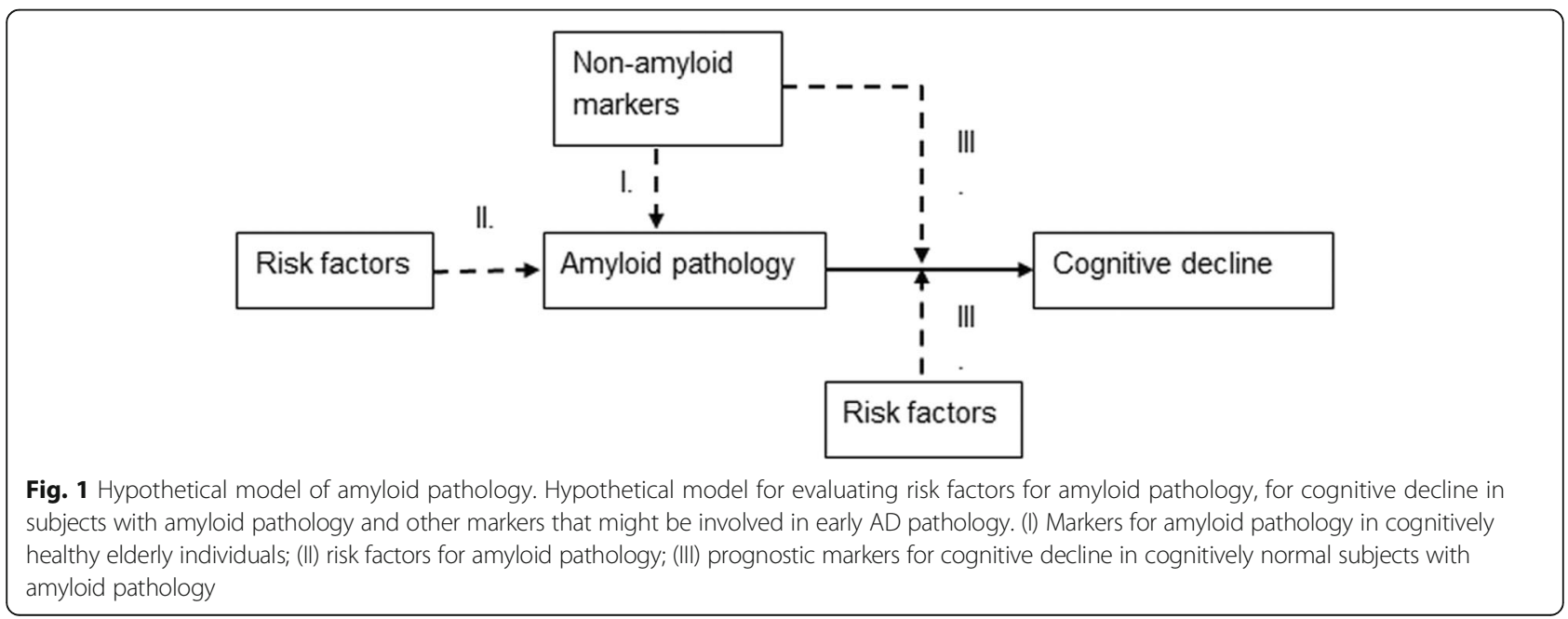


(EMIF-AD) project, which aims to facilitate the development of treatment for $\mathrm{AD}$ in nondemented subjects (http://www.emif.eu/) by discovering and validating diagnostic markers, prognostic markers, and risk factors for $\mathrm{AD}$ in nondemented subjects using existing data resources where possible.

\section{Sample selection}

We included 81 cognitively normal participants from the ACPRC. The ACPRC originally comprised over 6000 adults from the North of England, UK, who underwent detailed batteries of cognitive function biannually until 2003 [26]. In 1999 and 2000, active members of this cohort were invited and consented to provide a deoxyribonucleic acid (DNA) sample to the Dyne-Steel DNA Archive for study of Cognitive Genetics in later life. In 2003, a subsample of 500 Manchester volunteers underwent detailed physical examination and provided samples of saliva, serum, and plasma. Over time, the cohort has reduced in size through attrition, largely by mortality, to a number of approximately 660 volunteers. Since 2003, study participants have been assessed biannually with a smaller battery of tests and rating scales in order to diagnose pathological cognitive impairment and emotional problems. The current study coincides with the fourth wave of follow-up investigations. In Amsterdam, monozygotic twins were recruited from the NTR [29]. The NTR started recruiting adolescent and adult twins and their relatives in 1987 and had included over 200,000 participants by 2012 [27]. Twins who gave consent for the NTR also allow researchers to approach them for participation in scientific studies. From 1991 onward, participants completed extensive questionnaires every 2 or 3 years and DNA was collected in the NTR-Biobank project [30]. Smaller subgroups of participants underwent biomarker collection such as laboratory tests, electroencephalogram, or magnetic resonance imaging (MRI) [31-33]. The current study is a new NTR sub study.

\section{Ethical considerations}

The National Research Ethics Service Committee North West-Greater Manchester South performed ethical approval of the study in Manchester. The Medical Ethics Review Committee of the VU University Medical Center performed approval of the study in Amsterdam. Research was performed according to the principles of the Declaration of Helsinki and in accordance with the Medical Research Involving Human Subjects Act and codes on 'good use' of clinical data and biological samples as developed by the Dutch Federation of Medical Scientific Societies. All participants gave written informed consent.

\section{Inclusion criteria}

Inclusion criteria for the PreclinAD cohort were age 60 years and older, a delayed recall score above $-1.5 \mathrm{SD}$ of demographically adjusted normative data on the Consortium to Establish a Registry for Alzheimer's Disease 10-word list [34, 35], a Telephone Interview for Cognitive Status-modified score of 23 or higher [36], a 15-item Geriatric Depression Scale score $<11$ [37], and a Clinical Dementia Rating score of 0 [38] (Additional file 1: Table S1).

\section{Exclusion criteria}

To avoid possible interference with normal cognition, subjects with the following medical conditions, at present or in the past, were excluded: diagnosis of mild cognitive impairment $(\mathrm{MCI})$, probable $\mathrm{AD}$ or other neurodegenerative disorders such as Huntington disease, cortical basal degeneration, multiple system atrophy, Creutzfeldt-Jakob disease, primary progressive aphasia or Parkinson's disease, stroke resulting in physical impairment, epilepsy with current use of antiepileptic drugs, brain infection (e.g., herpes simplex encephalitis), brain tumor, severe head trauma with loss of consciousness longer than $5 \mathrm{~min}$, cancer with terminal life expectancy, untreated vitamin B12 deficiency, diabetes mellitus, thyroid disease, schizophrenia, bipolar disorders, or recurrent psychotic disorders. Furthermore, a history of recreational drug use, alcohol consumption $>35$ units per week $(1$ unit $=10 \mathrm{ml}$ or $8 \mathrm{~g}$ of pure alcohol), use of high-dose benzodiazepine, lithium carbonate, antipsychotics (including atypical agents), high-dose antidepressants, or Parkinson's disease medication were exclusion criteria. Finally, subjects who were not able to attend the hospital due to physical morbidity or illness or who had a contraindication for MRI (e.g., metal implants, pacemaker, etc.) were excluded (Additional file 1: Table S1).

\section{Data collection \\ Neuropsychological testing battery and questionnaires}

During a 4-h screening research facility visit (Manchester) or home visit (Amsterdam), participants underwent extensive neuropsychological testing and questionnaires. A complete overview of the neuropsychological testing battery and questionnaires is presented in Additional file 2: Table S2 and Additional file 3: Table S3, respectively. In short, we assessed memory function with the Rey auditory verbal learning task [39], visual association task [40], face-name associative memory examination [41], Rey complex figure recall [42], CANTAB paired associate learning [43], and digit span [44]. We also tested verbal fluency, naming [45], visuo-constructional skills, and executive functions [42, 46, 47] (see Additional file 2: Table S2). Using questionnaires we assessed social and physical activities [48-50], sleep quality [51, 52], activities 
of daily living [53, 54], memory complaints [55], and psychiatric symptoms [56] (see Additional file 3: Table S3).

\section{Physical examination}

Data on waist circumference, hip circumference, body mass index, resting blood pressure, heart rate, and grip strength of the dominant hand were collected for all participants (Table 1). In Manchester, an ankle/brachial pressure index and a 4-min walking test were also performed. In Amsterdam, a trained physician performed exploratory neurological examination. In addition, bioelectrical impedance analysis, repeated resting blood pressure measurement, and lead 1 of an electrocardiogram (measured by holding a Diagnostick [57] for 1 min) were performed and a color photograph of the face of each participant was taken. See Table 1 and Additional file 4: Table S4 for all biomarker data availability.

\section{Blood collection}

For all participants, $50 \mathrm{ml}$ of blood was collected in the morning, after $2 \mathrm{~h}$ of fasting, including EDTA blood for DNA isolation, plasma, and buffy coat, clotted blood for serum, and Paxgene tubes for RNA isolation. Immediate plasma analysis was performed for complete blood count, hemoglobin A1C, 2-h fasting glucose, liver enzymes, lipid spectrum, C-reactive protein, erythrocyte sedimentation rate, thyroid stimulating hormone, and vitamin B12. EDTA tubes with anticoagulated whole blood were centrifuged at $1300-2000 \times g$ for $10 \mathrm{~min}$, and plasma and remaining buffy coat were, like whole blood for collecting serum, aliquoted according to the standardized operating procedures of the BIOMARKAPD project [58] in aliquots of $0.25-0.5 \mathrm{ml}$ and stored locally until analysis. All samples were stored at $-80{ }^{\circ} \mathrm{C}$ within $2 \mathrm{~h}$. Two 2.5-ml Paxgene tubes were stored at room temperature for a minimum of $2 \mathrm{~h}$ and a maximum of $72 \mathrm{~h}$, before they were frozen at $-20^{\circ} \mathrm{C}$ until RNA isolation. The EDTA whole blood tube for DNA analysis was stored at $-20{ }^{\circ} \mathrm{C}$ until isolation.

\section{DNA and RNA collection}

Extraction of DNA and RNA from peripheral blood samples was performed at both sites. In addition, at the Amsterdam site, buccal cells were collected for zygosity, genome-wide association studies, and epigenetics [59]. Amsterdam participants were genotyped on the Affymetrix Axiom array and the Affymetrix 6 array [60]; these were first cross-chip imputed following the protocols described by Fedko et al. [61] and then imputed into HRC with the Michigan Imputation server [62]. The APOE genotypes were assessed using isoforms in Manchester as described by Ghebranious et al. [63]. In Amsterdam, the APOE genotype was assessed using imputed dosages of the SNPs rs429358 (APOE $\varepsilon 4$, imputation quality $=0.956)$ and rs7412 (APOE $\varepsilon 2$, imputation quality $=0.729)$ [64].

\section{Ultrasound carotid artery}

In Manchester, a duplex ultrasound scan of the left and right carotid arteries was performed to collect data on velocity, vessel thickness, stenosis, and plaques rated according to the North American Symptomatic Carotid Endarterectomy Trial guidelines [65]. In Amsterdam, a duplex ultrasound scan of the right carotid artery was performed to assess intima media thickness and distension using ArtLab software [66-68].

\section{Magnetic resonance imaging}

Acquisition protocol In Manchester, brain scans were performed at the Wellcome Trust Manchester Clinical Research Facility (Central Manchester University Hospital NHS Foundation Trust). All MRI investigations were performed on a $3 \mathrm{~T}$ Philips Achieva scanner using a 32-channel head coil. Participants underwent an MRI protocol that included 3D-T1, 3D fluid-attenuated inversion recovery (FLAIR), pseudocontinuous arterial spin labeling (ASL), and quantitative magnetization transfer scans. In Amsterdam, brain scans were also obtained using a $3 \mathrm{~T}$ Philips Achieva scanner equipped with an eight-channel head coil. The MRI protocol included structural 3D-T1, FLAIR, pseudocontinuous ASL, susceptibility weighted imaging (SWI), diffusion tensor imaging (DTI), and $6 \mathrm{~min}$ of resting state functional MRI (rs-fMRI). The MRI settings are presented in Additional file 5: Table S5.

Visual assessment All MRI scans were reviewed for incidental findings by an experienced neuroradiologist, and visually rated by a single experienced rater (MtK) who was blinded to demographic information and twin pairing at the moment of rating. White matter hyperintensities were visually assessed on the FLAIR images using the 4-point Fazekas scale (none, punctuate, early confluent, confluent) [69]. Lacunes were defined as deep lesions from 3 to $15 \mathrm{~mm}$ with CSF-like signal on T1-weighted and FLAIR images. Microbleeds were assessed on SWI scans and defined as rounded hypointense homogeneous foci of up to $10 \mathrm{~mm}$ in the brain parenchyma. Medial temporal lobe atrophy was assessed on coronal reconstructions of the T1-weighted images using a 5-point visual rating scale [70]. Global cortical atrophy was rated on transversal FLAIR images using a 4-point scale [71]. Posterior cortical atrophy was assessed using a 4-point visual rating scale [72].

\section{Amyloid positron emission tomography}

$\left[{ }^{18} \mathrm{~F}\right]$ flutemetamol In both centers, $\left[{ }^{18} \mathrm{~F}\right]$ flutemetamol was used as a fibrillar amyloid radiotracer. 
Table 1 Sample characteristics

\begin{tabular}{|c|c|c|c|c|c|c|}
\hline Demographic & $n$ & $\begin{array}{l}\text { Combined sample } \\
(n=285)\end{array}$ & $n$ & $\begin{array}{l}\text { Amsterdam site } \\
(n=204)\end{array}$ & $n$ & $\begin{array}{l}\text { Manchester site } \\
(n=81)\end{array}$ \\
\hline Age (years) & 285 & $\begin{array}{l}75.0(9.7) \\
\text { (range 60-95) }\end{array}$ & 204 & $\begin{array}{l}70.8(7.8) \\
\text { (range 60-94) }\end{array}$ & 81 & $\begin{array}{l}85.7(4.3)^{* * *} \\
\text { (range 79-95) }\end{array}$ \\
\hline Gender (\% female) & 285 & $182(64 \%)$ & 204 & $119(58 \%)$ & 81 & $63(78 \%)^{* *}$ \\
\hline Education (years) & 278 & $14.8(4.2)$ & 204 & $14.9(4.5)$ & 74 & $14.2(3.0)$ \\
\hline NART & 285 & $41.9(6.0)$ & 204 & $41.2(6.4)$ & 81 & $43.7(4.3)^{* * *}$ \\
\hline MMSE & 281 & $28.9(1.2)$ & 204 & $28.9(1.2)$ & 77 & $28.7(1.3)$ \\
\hline TICS-m & 282 & $28.3(3.2)$ & 204 & $28.3(3.0)$ & 78 & $28.5(3.7)$ \\
\hline CERAD 10-word recall & 285 & $22.8(3.3)$ & 204 & $22.0(3.0)$ & 81 & $24.8(3.3)^{* * *}$ \\
\hline GDS & 282 & $1.0(1.5)$ & 204 & $0.7(1.2)$ & 78 & $1.9(1.7)^{* * *}$ \\
\hline CDR total & 284 & $0(0.1)$ & 204 & 0 & 80 & $0.03(0.1)^{*}$ \\
\hline CDR sum of boxes & 284 & $0.03(0.1)$ & 204 & 0 & 80 & $0.1(0.3)^{* *}$ \\
\hline APOE e4 carrier & 282 & 85 (30\%) & 202 & $66(33 \%)$ & 80 & $19(24 \%)$ \\
\hline APOE4 genotype & 282 & & 202 & & 80 & \\
\hline e2e2 & & $2(1 \%)$ & & $2(1 \%)$ & & - \\
\hline e2e3 & & $24(9 \%)$ & & $12(6 \%)$ & & $12(15 \%)$ \\
\hline e2e4 & & $9(3 \%)$ & & $6(3 \%)$ & & $3(4 \%)$ \\
\hline e3e3 & & $171(61 \%)$ & & $122(60 \%)$ & & 49 (61\%) \\
\hline e3e4 & & $69(25 \%)$ & & $54(27 \%)$ & & $15(19 \%)$ \\
\hline e4e4 & & $7(3)$ & & $6(3 \%)$ & & $1(1 \%)$ \\
\hline Family history dementia & 273 & 106 (39\%) & 203 & $92(45 \%)$ & 70 & $14(20 \%)^{* * *}$ \\
\hline Diabetes type ॥ & - & - & 204 & $13(6 \%)$ & - & - \\
\hline Current smoker & 281 & $23(8 \%)$ & 203 & $21(10 \%)$ & 78 & $2(3 \%)$ \\
\hline Alcohol use present & 282 & $224(79 \%)$ & 204 & 158 (77\%) & 78 & $66(85 \%)$ \\
\hline Blood pressure (mmHg) & 281 & $152(21) / 80(12)$ & 202 & $155(21) / 83(11)$ & 79 & $143(19) / 70(10)^{* * *}$ \\
\hline Pulse rate (beats/min) & 279 & $66(11)$ & 202 & $65(11)$ & 77 & $69(10)^{* *}$ \\
\hline Height (m) & 283 & $1.66(0.10)$ & 204 & $1.69(0.09)$ & 79 & $1.60(0.08)^{* * *}$ \\
\hline Weight (kg) & 283 & $73.1(14.0)$ & 204 & 75.7 (13.6) & 79 & $66.6(13.0)^{* * *}$ \\
\hline Body mass index & 283 & $26.3(4.0)$ & 204 & $26.4(3.8)$ & 79 & $26.1(4.3)$ \\
\hline Waist circumference (cm) & 282 & $93.4(13.6)$ & 203 & $94.7(12.0)$ & 79 & $89.9(16.6)^{* *}$ \\
\hline Hip circumference (cm) & 234 & $101.9(11.4)$ & 155 & $102.6(9.8)$ & 79 & $100.5(14.0)$ \\
\hline Grip strength (kg) & 283 & $28.5(11.3)$ & 204 & $30.9(10.9)$ & 79 & $22.2(9.8)^{* * *}$ \\
\hline CSF Aß1-42 (pg/ml) & - & - & 126 & $889(314)$ & - & - \\
\hline CSF Aß1-40 (pg/ml) & - & - & 126 & $9592(2844)$ & - & - \\
\hline Ratio CSF A $\beta 1-42 / 1-40$ & - & - & 126 & $0.10(0.03)$ & - & - \\
\hline CSF total-tau (pg/ml) & - & - & 126 & $412(143)$ & - & - \\
\hline CSF p-tau 181 (pg/ml) & - & - & 126 & $76(44)$ & - & - \\
\hline Visual read PET abnormal & 272 & $58(22 \%)$ & 196 & $32(16 \%)$ & 76 & $26(34 \%)^{* *}$ \\
\hline Fazekas score & 279 & $1.3(0.9)$ & 199 & $1.2(0.8)$ & 80 & $1.7(0.8)^{* * *}$ \\
\hline Medial temporal lobe atrophy score (average left and right) & 277 & $0.7(0.7)$ & 197 & $0.6(0.7)$ & 80 & $0.9(0.6)^{*}$ \\
\hline Parietal atrophy (average left and right) & 279 & $1.1(0.7)$ & 199 & 1.1. $(0.7)$ & 80 & $1.2(0.6)^{*}$ \\
\hline
\end{tabular}

Data presented as mean (standard deviation) or $n$ (\%)

NART National Adult Reading Test, MMSE Mini-Mental State Examination, TICS-m Modified Telephone Interview for Cognitive Status, CERAD Consortium to Establish A Registry for Alzheimer's Disease, GDS Geriatric Depression Scale, CDR Clinical Dementia Rating, APOE Apolipoprotein E, CSF cerebrospinal fluid, $A \beta$ amyloid beta, p-tau phosphorylated tau, $P E T$ positron emission tomography

${ }^{* * *} p<0.001,{ }^{* *} p<0.01,{ }^{*} p<0.05$, group difference assessed with $t$ test or chi-square test 
$\left[{ }^{18} \mathrm{~F}\right]$ flutemetamol is an ${ }^{11} \mathrm{C}$-Pittsburgh compound $\mathrm{B}$ (PiB) derivative radiolabeled with ${ }^{18} \mathrm{~F}$ and has structural similarity to $\mathrm{PiB}$, which is a frequently used compound for in-vivo detection of amyloid plaques [73]. In Manchester, the tracer $\left[{ }^{18} \mathrm{~F}\right]$ flutemetamol was produced at the Wolfson Molecular Imaging Centre (WMIC) Good Manufacturing Practice radiochemistry facility using General Electric Healthcare's (GEHC) FASTlab and cassettes. For Amsterdam, the same tracer was produced at the Cyclotron Research Center of the University of Liège (Liège, Belgium). GEHC was responsible for production and transportation of $\left[{ }^{18} \mathrm{~F}\right]$ flutemetamol. Prior $\left[{ }^{18} \mathrm{~F}\right]$ flutemetamol studies showed good brain uptake and radiation dosimetry similar to other radiopharmaceuticals in clinical use, test-retest variability for image quantitation differentiation between healthy participants and patients with $\mathrm{AD}$, and the ability to detect brain $\mathrm{A} \beta$ [73].

Acquisition protocol At both sites, all participants were scanned dynamically from 0 to $30 \mathrm{~min}$ and then again from 90 to $110 \mathrm{~min}$ after intravenous injection of $185 \mathrm{MBq}( \pm 10 \%)\left[{ }^{18} \mathrm{~F}\right]$ flutemetamol. The initial scan (0-30 $\mathrm{min})$ was shortened or omitted if it was not accepted or tolerated by the participant. The second time window (90-110 $\mathrm{min}$ ) is the recommended interval for assessment of amyloid biomarker abnormality. In Manchester, all PET scans were performed on a high-resolution research tomograph brain scanner (HRRT; Siemens/CTI, Knoxville, TN, USA) at the WMIC of the University of Manchester. Two 7-min transmission scans using a ${ }^{137} \mathrm{Cs}$ point source were acquired for subsequent attenuation and scatter correction; one prior to the first emission scan, and another following the second emission scan [74, 75]. In Amsterdam, all PET scans were performed using a Philips Ingenuity Time-of-Flight PETMRI scanner at the Department of Radiology \& Nuclear Medicine of the VU University Medical Center. Immediately prior to each part of the PET scan, a dedicated MR sequence (atMR) was performed for attenuation correction of the PET image [76]. For both sites, the first dynamic emission scan was reconstructed into 18 frames with progressive increase in frame length $(6 \times 5 \mathrm{~s}, 3 \times 10 \mathrm{~s}$, $4 \times 60 \mathrm{~s}, 2 \times 150 \mathrm{~s}, 2 \times 300 \mathrm{~s}, 1 \times 600 \mathrm{~s})$. The second part of the scan consisted of $4 \times 5$-min frames. During scanning, the head was immobilized to reduce movement artifacts using laser beams.

Visual assessment All $\left[{ }^{18} \mathrm{~F}\right]$ flutemetamol amyloid PET scans were checked for movement and the frames were summed to obtain a static image (90-110 min). PET images were visually read as abnormal or normal by an experienced reader (SFC in Manchester and BNMvB in Amsterdam), blinded to clinical and demographic data, according to GEHC guidelines described in the summary of product characteristics [77].

\section{CSF collection (Amsterdam site only)}

Up to $20 \mathrm{ml}$ of CSF was obtained by lumbar puncture in Sarstedt polypropylene syringes using a Spinocan 25-gauge needle in one of the intervertebral spaces between L3 and S1. One milliliter was immediately processed for leukocyte count, erythrocyte count, glucose, and total protein. The remaining CSF was mixed and centrifuged at $1300-2000 \times g$ for $10 \mathrm{~min}$ at $4{ }^{\circ} \mathrm{C}$. Supernatants were stored in aliquots of $0.25-0.5 \mathrm{ml}$ and frozen within 2 $\mathrm{h}$ at $-80{ }^{\circ} \mathrm{C}$ and stored for future biomarker discovery studies [78]. Levels of amyloid $\beta 1-40$ and $\beta 1-42$ were analyzed using kits from ADx Neurosciences/Euroimmun according to the manufacturer's instructions. All samples were measured in kits from the same lot.

\section{Magnetoencephalography (Amsterdam site only)}

Magnetoencephalography (MEG) measurements were recorded using a 306-channel, whole-head MEG system (ElektaNeuromag Oy, Helsinki, Finland) in a magnetically shielded room (Vacuumschmelze GmbH, Hanau, Germany). Participants were instructed to lie on a bed with their eyes closed but to stay awake and reduce eye movements in order to minimize artifacts. Participants were scanned for $5 \mathrm{~min}$ with eyes closed, 2 min with eyes open, and another $5 \mathrm{~min}$ with eyes closed. On MEG we used source-reconstructed time series (https://doi.org/ 10.1016/j.neuroimage.2011.11.005) to extract both frequency spectrum properties (relative band power and peak frequency) and functional connectivity between regions, as well as network topology using modern network theory (synchronization likelihood, modularity, path length, phase lag index) $[79,80]$. These analysis techniques were applied using BrainWave software (http://home.kpn.nl/stam7883/ brainwave.html) [81] and inhouse MATLAB scripts (MATLAB Release 2012a; The MathWorks, Inc., Natick, MA, USA).

\section{Ophthalmological markers (Amsterdam site only) Exploratory eye examination An exploratory eye examination including measurement of best corrected visual acuity, refractive error, and intra-ocular pressure (noncontact tonometry) was performed. In a subsample $(n=50)$, slit lamp examination by a trained physician was performed as well.}

Ocular coherence tomography Ocular coherence tomography (OCT) was performed using the Heidelberg Spectralis. With OCT we measured retinal nerve fiber layer tissue, total macular thickness, and the thickness of macular individual retinal layers using the built-in segmentation software from the Spectralis [82], which 
might correlate with cerebral amyloid pathology [83]. With the same device, fundus autofluorescence was performed to try to detect degenerative retinal abnormalities possibly related to amyloid pathology [83, 84].

Retinal imaging Using a nonmydriatic camera (Topcon), two digital images (mostly $50^{\circ}$, and some $30^{\circ}$ ) per eye were taken of the retina-one centered to the macula, and the other to the optic nerve head-after pupil dilation with tropicamide. On the digitalized fundoscopy image we measured retinal vascular parameters using the Singapore I vessel Assessment software [85].

\section{Data management}

Data were stored in the online database CASTOR (https://castoredc.com/) with restricted access. Each site provided clinical information and sample information to the database according to a predefined case report form. Blood and CSF samples, PET and MRI scans, and MEG data are stored locally until centralized analysis.

\section{Follow-up visit}

A follow-up visit including neuropsychological testing, questionnaires at both sites, and physical examination, blood sampling, buccal cell collection, and lumbar puncture in a subset will be performed after 21 months \pm 3 months.

Follow-up started in February 2017 and is still ongoing. So far 241 individuals have been invited, and of those 221 (92\%) participated in the follow-up.

For the twin pairs, an additional follow-up visit after 4 years is planned, starting in January 2019. This follow-up includes amyloid-PET, tau-PET, MRI, lumbar puncture, neuropsychological testing, questionnaires, physical examination, blood sampling, and buccal cell collection.

\section{Statistical approaches Group analysis}

The main outcome measure will be the presence of amyloid pathology as a dichotomous and continuous outcome measure. We aim to identify for each diagnostic modality the best set of predictors for amyloid pathology using step forward selection. The best predictors for each modality will be combined in a single risk score, based on the $\beta$ value of these predictors in the regression model. Analysis will be performed using multivariate multilevel generalized estimating equation analysis with correction for age, gender, education, and twin status (Amsterdam only) [86]. In addition, as there are differences between the cohorts, we will correct for cohort in the analysis and test interactions of predictor variables with cohort to check whether pooling the data may introduce a bias.

\section{Results}

Inclusion

Manchester

From the ACPRC, 321 subjects in total were invited by letter to participate in the PreclinAD study. From this selection, 81 subjects were included for participation (see Fig. 2a).

\section{Amsterdam}

In total 517 twins from the NTR were invited by letter. Of these, 100 complete pairs (99 MZ, one dizygotic, as confirmed with DNA analysis) and four singletons, of which the co-twin did not meet the inclusion criteria due to cognitive impairment of other neurological conditions, were included (see Fig. 2b). This also included one twin who appeared to be demented at baseline hospital visit, even though this subject passed the inclusion criteria at first, and one subject from a monozygotic triplet, which we included due to the unique opportunity to analyze a genetically identical triplet, but this subject did not meet the inclusion criteria due to MCI. All participants, except for one twin pair, have European descent. When analyzing genetic data this twin pair will be excluded from the analysis.

\section{Demographics and biomarkers}

Participants were on average 74.8 years old, $64 \%$ female, and $30 \%$ APOE $\varepsilon 4$ carriers; for further baseline characteristics see Table 1. Participants tested in Manchester were older compared to Amsterdam participants $(85.7$ vs 70.8 years, $p<0.001$ ) and more often female (78 vs $58 \%$, $p<0.01)$. Manchester participants also had a higher intelligence score according to the Adult Reading Task (43.7 vs $41.2, p<0.001$ ), less often a family member with dementia ( 20 vs $45 \%, p<0.001$ ), lower blood pressure, $(143 / 70$ vs $155 / 83 \mathrm{mmHg}, p<0.001)$, and higher white matter lesion load according to the Fazekas score (1.7 vs $1.2, p<0.001$ ) (Table 1 ).

Amyloid data were available for 275 participants (Manchester $n=76$, Amsterdam $n=199$ ). In Amsterdam, 123 participants had both CSF and PET available, 73 PET only, and three CSF only. For 10 participants we were unable to assess their amyloid status: six participants were not able to attend the hospital after inclusion, one participant did not undergo PET due to meningiomas on MRI, two participants suffered from claustrophobia during the hospital visit, and one participant had a panic attack before injection of the PET tracer. Dynamic PET scans were present in 261 participants: four participants failed their dynamic scan due to logistic problems, and in seven participants quality control of the images failed.

\section{Amyloid pathology}

Of the 272 participants with a static PET amyloid measure available, 58 (21\%) had an abnormal PET scan as 


\section{a}

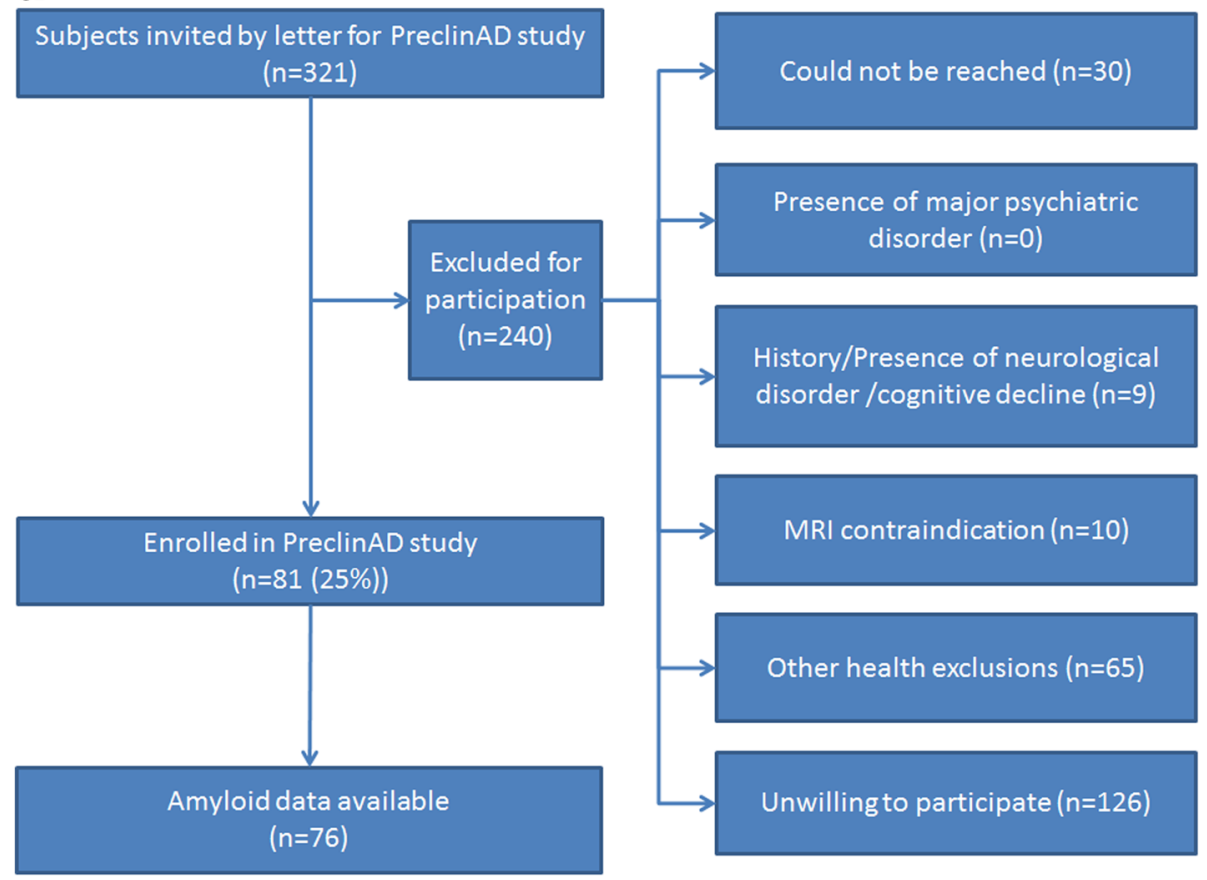

\section{b}

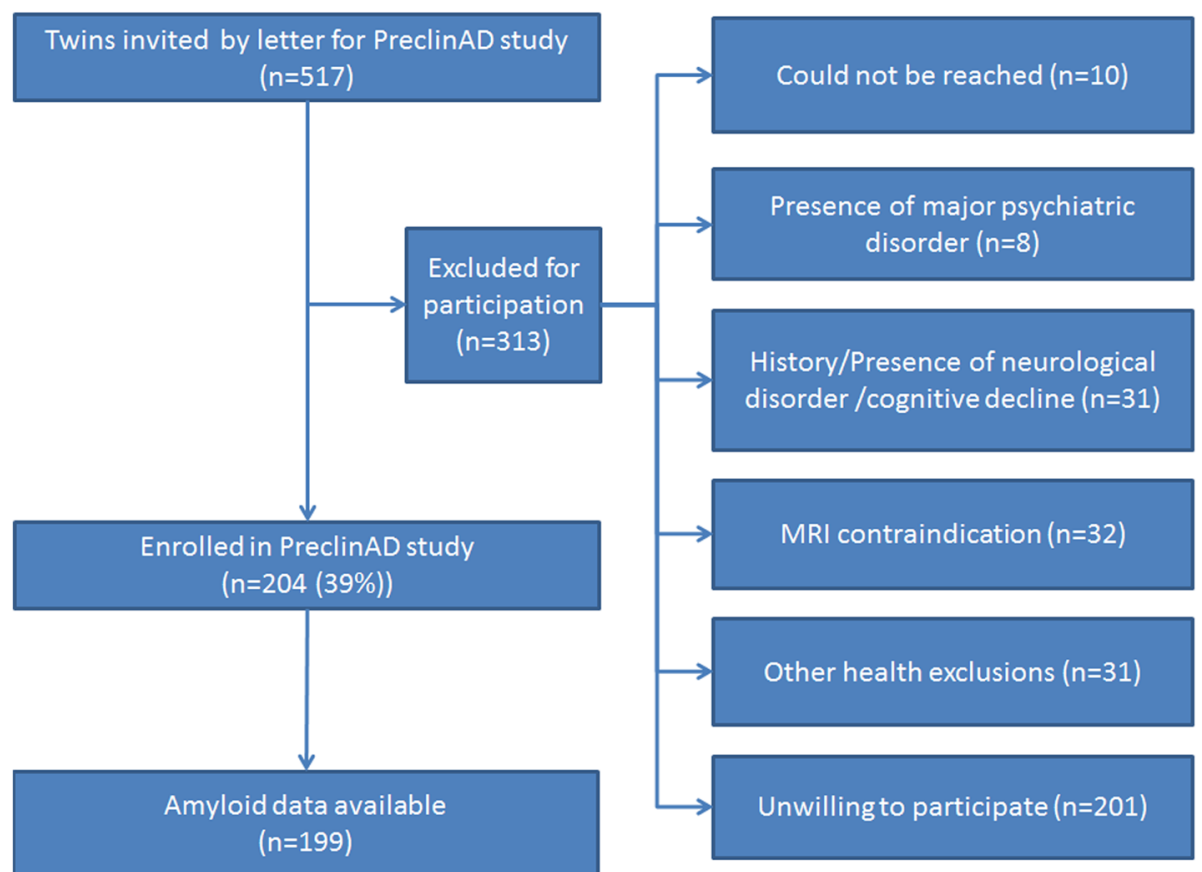

Fig. 2 Inclusion flow chart for participants from a Manchester invited subjects selected from a sample of 660 subjects who were part of Manchester and Newcastle Age and Cognitive Performance Research Cohort (ACPRC, Manchester) at time of recruitment and $\mathbf{b}$ from Amsterdam invited twins selected from a sample of 678 monozygotic twins who were actively registered in Netherlands Twin Register (Amsterdam) at time of recruitment 
visually read on a summed static PET image. An abnormal PET was less common in Amsterdam (16\%) than in Manchester (34\%) $(p<0.001)$. The prevalence of abnormal amyloid PET scans was higher in older age groups (Fig. 3).

\section{Discussion}

The PreclinAD study is a prospective cohort study of 285 cognitively normal elderly individuals with extensive phenotyping for amyloid pathology, neurodegeneration markers, cognition, and lifestyle factors.

We noted some differences in baseline characteristics between the Manchester and Amsterdam sites. This could mainly be explained by the higher age in the Manchester substudy. The prevalence of amyloid pathology increased with age, although the prevalence was somewhat lower than would be expected based on a large subject-level meta-analysis, in particular in the age range below 80 years [4]. This might be explained by the relatively healthy sample of participants, due to the strict inclusion and exclusion criteria.

The Amsterdam sub study is the first to assess a wide range of $\mathrm{AD}$ markers in a large sample of cognitively normal monozygotic twin pairs above age 60 years. The uniqueness of studying a cohort of twin pairs sharing $100 \%$ of their genetic material enables us to further explore the nature of the relation between $\mathrm{AD}$ markers. If MZ twin pairs are highly similar for AD markers, this suggests involvement of shared genetic and/or shared environmental factors, whereas within-pair differences indicate the involvement of unique environmental factors [87]. The strength of the MZ twin within-pair difference model further enables us to identify environmental risk factors (e.g., smoking, alcohol use, diet, sleep, physical activity, cognitive activity, and education) that, either directly or indirectly through epigenetic mechanisms, explain observed differences in AD markers within pairs. This may provide clues for novel preventive and therapeutic strategies. However, this model also has the disadvantage that, because $\mathrm{MZ}$ twins are genetically identical, we have to correct for twin dependency in all analysis, which may reduce statistical power [86]. Further, we did not include dizygotic twins in the current study, because this optimizes power for twin difference analysis, thereby strengthening the search for environmental risk factors influencing $\mathrm{AD}$ development. However, this has the disadvantage that the relative contribution of shared genetic and shared environmental factors to within-pair correlations cannot be estimated. Still, previous studies in elderly twins suggested that the contribution of shared environment at older age is highly limited, possibly because subjects have already been living apart for a longer period of time $[88,89]$.

A strength of our study, compared to other studies on preclinical $\mathrm{AD}$, is that participants have been recruited from cohorts that have been ongoing for up to 20 years, which provides the possibility to test biomarkers, cognition, and lifestyle collected in the past as predictors for AD biomarkers. Our study design also has several limitations. First, although acquisition protocols were harmonized across sites, they were not always identical (e.g., use of HRRT vs PET-MR). For this reason, site will be used as a covariate in all analyses. Some of the biomarkers were only acquired at the Amsterdam site, which will reduce the statistical power for the analysis of these markers.

\section{Conclusions}

We collected a large European cognitively normal sample with an extensive panel of AD biomarkers available

\section{Percentage of subjects with abnormal PET by agegroup}

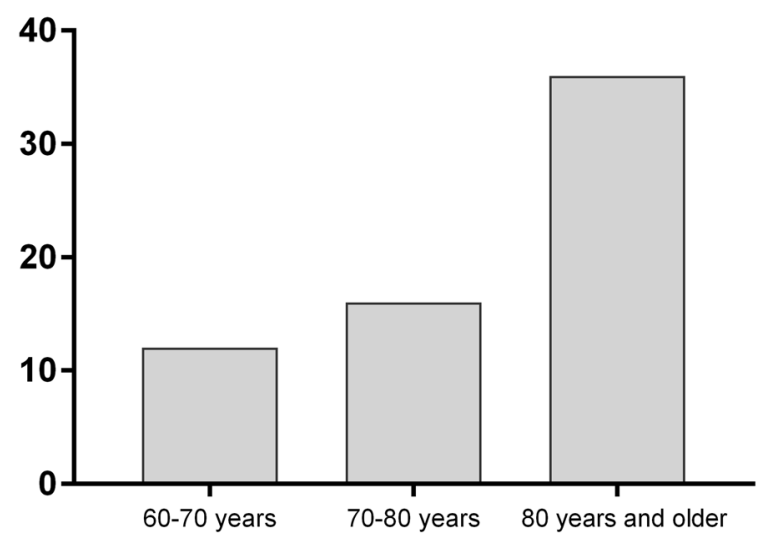

Fig. 3 Amyloid abnormality on PET scan per age group ( $n=58,22 \%)$. Abnormal PET scan visually read on summed static PET images: $12 \%$ of subjects aged $60-70$ years, $16 \%$ of subjects between 70 and 80 years, and $36 \%$ of subjects 80 years and older had abnormal PET scan 
at baseline, with clinical follow-up planned after 2 years, to identify healthy elderly individuals at risk for amyloid pathology and future cognitive decline. Results from this study will improve understanding of the pathophysiology of $\mathrm{AD}$ and thereby help to adapt the design of secondary prevention trials.

\section{Additional files}

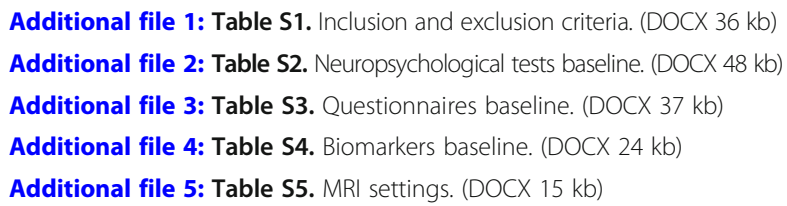

\section{Abbreviations}

ACPRC: Manchester and Newcastle Age and Cognitive Performance Research Cohort; AD: Alzheimer's disease; APOE: Apolipoprotein E; ASL: Arterial spin labeling; CSF: Cerebrospinal fluid; DTI: Diffusion tensor imaging; EDTA: Ethylene diamine tetra-acetic acid; EMIF-AD: European Medical Information Framework for AD; FLAIR: 3D fluid-attenuated inversion recovery; GEHC: General Electric Healthcare; HRRT: High-resolution research tomograph; MCl: Mild cognitive impairment; MEG: Magnetoencephalography; MRI: Magnetic resonance imaging; MZ: Monozygotic; NTR: Netherlands Twins Register; OCT: Ocular coherence tomography; PET: Positron emission tomography; rs-fMRl: Resting state functional MRI; SWI: Susceptibility weighted imaging; WMIC: Wolfson Molecular Imaging Centre

\section{Acknowledgements}

The authors want to thank all PreclinAD participants for their efforts to join and complete this demanding study. Thanks to Heleen Labuschagne, Leoni Goossens, Lisanne Labuschagne, Naomi Prent, Diederick de Leeuw, Jasper van Dam, Eva Postma, Esmee Runhardt, and Djoeke Rondagh for help with EMIF-AD data collection.

\section{Funding}

This work has received support from the EU/EFPIA Innovative Medicines Initiative Joint Undertaking EMIF grant agreement $n^{\circ} 115372$. This work also received in-kind sponsoring of the Diagnostick device from Applied Biomedical Systems BV, the CANTAB device from Cambridge Cognition, the CSF assay from ADx NeuroSciences, and the PET tracer from GE Health Care.

\section{Availability of data and materials}

The datasets used and/or analyzed during the current study are available from the corresponding author on reasonable request.

\section{Authors' contributions}

PJV and KH conceived the study and designed the protocol. EK, SFC, MtK, AdB, JT, CA, H-TN, JAvdK, and LW collected data. EK, SFC, MtK, MY, and RH performed image analysis. EK and AdB performed statistical analysis. EK, SFC, MtK, and AdB drafted the manuscript. JT, CA, LW, H-TN, JAvdK, MY, MD, SDM, AH, FHB, CET, EHS, ACM, FDV, RH, NP, AAL, FB, BNMvB, DIB, PS, KH, and PJV edited the manuscript for critical content. PJV and $\mathrm{KH}$ provided overall study supervision. All authors read and approved the final version of the manuscript

\section{Ethics approval and consent to participate}

The National Research Ethics Service Committee North West-Greater Manchester South performed ethical approval of the study for Manchester. The Medical Ethics Review Committee of the VU University Medical Center performed approval of the study for Amsterdam. The research is performed according to the principles of the Declaration of Helsinki and in accordance with the Medical Research Involving Human Subjects Act and codes on 'good use' of clinical data and biological samples as developed by the Dutch Federation of Medical Scientific Societies. All participants will give written informed consent.

\section{Consent for publication}

Not applicable.

\section{Competing interests}

CET has functioned on advisory boards of Fujirebio and Roche, received nonfinancial support in the form of research consumables from ADxNeurosciences and Euroimmun, and performed contract research or received grants from Janssen Prevention Center, Boehringer, Brainsonline, AxonNeurosciences, EIP farma, and Roche. FB is supported by the NIHR UCLH Biomedical Research Center and has received consulting fees or honoraria from Novartis, Roche, Bayer-Schering, Biogen-IDEC, Genzyme-Sanofi, TEVA, Merck-Serono, Jansen Research, IXICO Ltd, GeNeuro, and Apitope Ltd. AH reports reimbursements for conference from Elekta Oy. BNMvB is a trainer for the visual interpretation of $\left[{ }^{18}\right.$ F $]$ flutemetamol PET scans, and does not receive personal compensation for this. The remaining authors declare that they have no competing interests

\section{Publisher's Note}

Springer Nature remains neutral with regard to jurisdictional claims in published maps and institutional affiliations.

\section{Author details}

${ }^{1}$ Alzheimer Center, Department of Neurology, VU University Medical Center, Neuroscience Amsterdam, PO Box 7057, 1007 MB Amsterdam, The Netherlands. ${ }^{2}$ Wolfson Molecular Imaging Centre, Division of Neuroscience and Experimental Psychology, University of Manchester, Manchester, UK. ${ }^{3}$ Department of Biological Psychology, VU University, Neuroscience Amsterdam, Amsterdam, The Netherlands. ${ }^{4}$ Department of Ophthalmology, VU University Medical Center, Neuroscience Amsterdam, Amsterdam, The Netherlands. ${ }^{5}$ Department of Radiology \& Nuclear Medicine, VU University Medical Center, Neuroscience Amsterdam, Amsterdam, The Netherlands. ${ }^{6}$ Neurochemistry Laboratory, Department of Clinical Chemistry, VU University Medical Center, Neuroscience Amsterdam, Amsterdam, The Netherlands. ${ }^{7}$ Department of Clinical Neurophysiology, VU University Medical Center, Neuroscience Amsterdam, Amsterdam, The Netherlands. ${ }^{8}$ Department of Internal Medicine, VU University Medical Center, Neuroscience Amsterdam, Amsterdam, The Netherlands. 'Wolfson Molecular Imaging Centre, Division of Informatics, Imaging and Data Sciences, Faculty of Medicine, Biology and Health, University of Manchester, Manchester, UK. ${ }^{10}$ Institutes of Neurology \& Healthcare Engineering, UCL, London, UK. ${ }^{11}$ Department of Psychiatry and Neuropsychology, School for Mental Health and Neuroscience, Alzheimer Center Limburg, Maastricht University, Maastricht, The Netherlands.

Received: 13 March 2018 Accepted: 12 July 2018

Published online: 04 August 2018

\section{References}

1. Braak H, Braak E. Diagnostic criteria for neuropathologic assessment of Alzheimer's disease. Neurobiol Aging. 1997;18(4 Suppl):S85-8.

2. Bateman RJ, Xiong C, Benzinger TL, Fagan AM, Goate A, Fox NC, Marcus DS, Cairns NJ, Xie X, Blazey TM, et al. Clinical and biomarker changes in dominantly inherited Alzheimer's disease. N Engl J Med. 2012;367(9):795-804.

3. Villemagne VL, Burnham S, Bourgeat P, Brown B, Ellis KA, Salvado O, Szoeke C, Macaulay SL, Martins R, Maruff P, et al. Amyloid beta deposition, neurodegeneration, and cognitive decline in sporadic Alzheimer's disease: a prospective cohort study. Lancet Neurol. 2013;12:357-67.

4. Jansen WJ, Ossenkoppele R, Knol DL, Tijms BM, Scheltens P, Verhey FR, Visser PJ, Amyloid Biomarker Study G, Aalten P, Aarsland D, et al. Prevalence of cerebral amyloid pathology in persons without dementia: a metaanalysis. JAMA. 2015:313:1924-38.

5. Price JL, Morris JC. Tangles and plaques in nondemented aging and "preclinical" Alzheimer's disease. Ann Neurol. 1999:45:358-68.

6. Mintun MA, Larossa GN, Sheline YI, Dence CS, Lee SY, Mach RH, Klunk WE, Mathis CA, DeKosky ST, Morris JC. [11C]PIB in a nondemented population: potential antecedent marker of Alzheimer disease. Neurol. 2006;67:446-52.

7. Aizenstein HJ, Nebes RD, Saxton JA, Price JC, Mathis CA, Tsopelas ND, Ziolko SK, James JA, Snitz BE, Houck PR, et al. Frequent amyloid deposition without significant cognitive impairment among the elderly. Arch Neurol. 2008;65:1509-17.

8. Rowe CC, Ellis KA, Rimajova M, Bourgeat P, Pike KE, Jones G, Fripp J, Tochon-Danguy H, Morandeau L, O'Keefe G, et al. Amyloid imaging results from the Australian Imaging, Biomarkers and Lifestyle (AIBL) study of aging. Neurobiol Aging. 2010;31:1275-83. 
9. Chételat G, La Joie R, Villain N, Perrotin A, de La Sayette V, Eustache F, Vandenberghe R. Amyloid imaging in cognitively normal individuals, at-risk populations and preclinical Alzheimer's disease. Neurolmage. 2013;2:356-65.

10. Dubois B, Feldman HH, Jacova C, Hampel H, Molinuevo JL, Blennow K, DeKosky ST, Gauthier S, Selkoe D, Bateman R, et al. Advancing research diagnostic criteria for Alzheimer's disease: the IWG-2 criteria. Lancet Neurol. 2014;13:614-29.

11. McKhann GM, Knopman DS, Chertkow H, Hyman BT, Jack CRJ, Kawas CH, Klunk WE, Koroshetz WJ, Manly JJ, Mayeux R, et al. The diagnosis of dementia due to Alzheimer's disease: recommendations from the National Institute on Aging-Alzheimer's Association workgroups on diagnostic guidelines for Alzheimer's disease. Alzheimers Dement. 2011;7:263-9.

12. Dickerson BC, Wolk DA. MRI cortical thickness biomarker predicts AD-like CSF and cognitive decline in normal adults. Neurology. 2011;78:84-90.

13. Lunnon K, Sattlecker M, Furney SJ, Coppola G, Simmons A, Proitsi P, Lupton MK, Lourdusamy A, Johnston C, Soininen $H$, et al. A blood gene expression marker of early Alzheimer's disease. J Alzheimers Dis. 2013;33:737-53.

14. Hye A, Riddoch-Contreras J, Baird AL, Ashton NJ, Bazenet C, Leung R, Westman E, Simmons A, Dobson R, Sattlecker M, et al. Plasma proteins predict conversion to dementia from prodromal disease. Alzheimers Dement. 2014;10(6):799-807. e792

15. Fjell AM, Walhovd KB, Fennema-Notestine C, McEvoy LK, Hagler DJ, Holland D, Blennow K, Brewer JB, Dale AM. Brain atrophy in healthy aging is related to CSF levels of Abeta1-42. Cereb Cortex. 2010;20:2069-79.

16. Corder EH, Saunders AM, Strittmatter WJ, Schmechel DE, Gaskell PC, Small $G W$, Roses AD, Haines $J$, Pericak-Vance MA. Gene dose of apolipoprotein E type 4 allele and the risk of Alzheimer's disease in late onset families. Science. 1993;261(5123):921-3.

17. Jack CRJ, Wiste HJ, Weigand SD, Knopman DS, Vemuri P, Mielke MM, Lowe V, Senjem ML, Gunter JL, Machulda MM, et al. Age, sex, and APOE epsilon4 effects on memory, brain structure, and beta-amyloid across the adult life span. JAMA Neurol. 2015;72:511-9.

18. Wirth M, Villeneuve S, La Joie R, Marks SM, Jagust WJ. Gene-environment interactions: lifetime cognitive activity, APOE genotype, and beta-amyloid burden. J Neurosci. 2014;34(25):8612-7.

19. Vos SJ, Xiong C, Visser PJ, Jasielec MS, Hassenstab J, Grant EA, Cairns NJ, Morris JC, Holtzman DM, Fagan AM. Preclinical Alzheimer's disease and its outcome: a longitudinal cohort study. Lancet Neurol. 2013;12:957-65.

20. Buckley RF, Hanseeuw B, Schultz AP, Vannini P, Aghjayan SL, Properzi MJ, Jackson JD, Mormino EC, Rentz DM, Sperling RA, et al. Region-specific association of subjective cognitive decline with tauopathy independent of global $\beta$-amyloid burden. JAMA Neurol. 2017;74(12):1455-63.

21. Lim $Y Y$, Maruff $P$, Pietrzak RH, Ellis KA, Darby D, Ames D, Harrington $K$, Martins RN, Masters $C L$, Szoeke $C$, et al. AB and cognitive change: examining the preclinical and prodromal stages of Alzheimer's disease. Alzheimers Dement. 2014;10(6):743-51. e741

22. Landau SM, Lu M, Joshi AD, Pontecorvo M, Mintun MA, Trojanowski JQ, Shaw LM, Jagust WJ. Alzheimer's Disease Neuroimaging Initiative. Comparing PET imaging and CSF measurements of A $\beta$. Ann Neurol. 2013; 74(6):826-36.

23. Zwan M, van Harten A, Ossenkoppele R, Bouwman F, Teunissen C, Adriaanse S, Lammertsma A, Scheltens P, van Berckel B, van der Flier W. Concordance between cerebrospinal fluid biomarkers and [11C]PIB PET in a memory clinic cohort. J Alzheimers Dis. 2014;41:801-7.

24. Mattsson N, Insel PS, Donohue M, Landau S, Jagust WJ, Shaw LM, Trojanowski JQ, Zetterberg H, Blennow K, Weiner MW, et al. Independent information from cerebrospinal fluid amyloid-beta and florbetapir imaging in Alzheimer's disease. Brain. 2015;138(Pt 3):772-83.

25. Palmqvist S, Mattsson N, Hansson O, Alzheimer's Disease Neuroimaging Initiative. Cerebrospinal fluid analysis detects cerebral amyloid-beta accumulation earlier than positron emission tomography. Brain. 2016;139(Pt 4):1226-36.

26. PMA R, et al. The University of Manchester longitudinal study of cognition in normal healthy old age, 1983 through 2003. Aging Neuropsychol C. 2004; 11:245-79.

27. Willemsen G, Vink JM, Abdellaoui A, den Braber A, van Beek JH, Draisma HH, van Dongen J, van 't Ent D, Geels LM, van Lien $R$, et al. The adult Netherlands twin register: twenty-five years of survey and biological data collection. Twin Res Hum Genet. 2013;16(1):271-81.

28. Gatz M, Reynolds CA, Fratiglioni L, Johansson B, Mortimer JA, Berg S, Fiske A, Pedersen NL. Role of genes and environments for explaining Alzheimer disease. Arch Gen Psychiatry. 2006;63(2):168-74.
29. Boomsma DI, de Geus EJ, Vink JM, Stubbe JH, Distel MA, Hottenga JJ, Posthuma D, van Beijsterveldt TC, Hudziak JJ, Bartels M, et al. Netherlands Twin Register: from twins to twin families. Twin Res Hum Genet. 2006;9(6): 849-57.

30. Willemsen G, de Geus EJ, Bartels M, van Beijsterveldt CE, Brooks Al, Estourgie-van Burk GF, Fugman DA, Hoekstra C, Hottenga JJ, Kluft K, et al. The Netherlands Twin Register biobank: a resource for genetic epidemiological studies. Twin Res Hum Genet. 2010;13(3):231-45.

31. van Beijsterveldt CE, van Baal GC, Molenaar PC, Boomsma DI, de Geus EJ. Stability of genetic and environmental influences on P300 amplitude: a longitudinal study in adolescent twins. Behav Genet. 2001;31(6):533-43.

32. Posthuma D, Meulenbelt I, de Craen AJ, de Geus EJ, Slagboom PE, Boomsma DI, Westendorp RG. Human cytokine response to ex vivo amyloid-beta stimulation is mediated by genetic factors. Twin Res Hum Genet. 2005;8(2):132-7.

33. den Braber A, van 't Ent D, Cath DC, Veltman DJ, Boomsma Dl, de Geus EJ. Brain activation during response interference in twins discordant or concordant for obsessive compulsive symptoms. Twin Res Hum Genet. 2012;15(3):372-83.

34. Morris JC, Heyman A, Mohs RC, Hughes JP, van Belle G, Fillenbaum G, Mellits ED, Clark C. The Consortium to Establish a Registry for Alzheimer's Disease (CERAD). Part I Clinical and neuropsychological assessment of Alzheimer's disease. Neurol. 1989;39:1159-65.

35. Aebi C. Validierung der neuropsychologischen Testbatterie CERAD-NP: eine Multi-Center Studie [Validation of the CERAD neuropsychological assessment battery: a multi-centre study]. Basel: University of Basel; 2002.

36. de Jager CA, Budge MM, Clarke R. Utility of TICS-M for the assessment of cognitive function in older adults. Int J Geriatr Psychiatry. 2003;18:318-24.

37. Yesavage JA, Brink TL, Rose TL, Lum O, Huang V, Adey M, Leirer VO. Development and validation of a geriatric depression screening scale: a preliminary report. J Psychiatr Res. 1982;17:37-49.

38. Morris JC. The Clinical Dementia Rating (CDR): current version and scoring rules. Neurol. 1993;43:2412-4.

39. Rey A. L'examen clinique en psychologie. Paris: Presses Universitaires de France; 1964.

40. Lindeboom J, Schmand B, Tulner L, Walstra G, Jonker C. Visual association test to detect early dementia of the Alzheimer type. J Neurol Neurosurg Psychiatry. 2002;73:126-33.

41. Rentz DM, Amariglio RE, Becker JA, Frey M, Olson LE, Frishe K, Carmasin J, Maye JE, Johnson KA, Sperling RA. Face-name associative memory performance is related to amyloid burden in normal elderly. Neuropsychologia. 2011:49:2776-83.

42. Meyers JE, Bayless JD, Meyers KR. Rey complex figure: memory error patterns and functional abilities. Appl Neuropsychol. 1996;3:89-92.

43. Robbins TW, James M, Owen AM, Sahakian BJ, Mclnnes L, Rabbitt P. Cambridge Neuropsychological Test Automated Battery (CANTAB): a factor analytic study of a large sample of normal elderly volunteers. Dementia. 1994:5:266-81.

44. Wechsler D. Manual for the Wechsler adult intelligence scale. San Antonio: The Psychological Corporation; 1997.

45. McKenna P, Warrington EK. Testing for nominal dysphasia. J Neurol Neurosurg Psychiatry. 1980;43:781-8.

46. Tombaugh TN. Trail Making Test A and B: normative data stratified by age and education. Arch Clin Neuropsychol. 2004;19:203-14.

47. Wechsler D. Wechsler adult intelligence scale-revised manual. New York: Psychological Corporation; 1981.

48. Jakobsson U. Using the 12-item short form health survey (SF-12) to measure quality of life among older people. Aging Clin Ex Res. 2007;19:457-64.

49. Landau SM, Marks SM, Mormino EC, Rabinovici GD, Oh H, O'Neil JP, Wilson RS, Jagust WJ. Association of lifetime cognitive engagement and low betaamyloid deposition. Arch Neurol. 2012;69:623-9.

50. Washburn RA, Smith KW, Jette AM, Janney CA. The Physical Activity Scale for the Elderly (PASE): development and evaluation. J Clin Epidemiol. 1993; 46:153-62.

51. Boeve BF, Molano JR, Ferman TJ, Smith GE, Lin SC, Bieniek K, Haidar W, Tippmann-Peikert M, Knopman DS, Graff-Radford NR, et al. Validation of the Mayo Sleep Questionnaire to screen for REM sleep behavior disorder in an aging and dementia cohort. Sleep Med. 2011;12:445-53.

52. Netzer NC, Stoohs RA, Netzer CM, Clark K, Strohl KP. Using the Berlin Questionnaire to identify patients at risk for the sleep apnea syndrome. Ann Intern Med. 1999;131:485-91. 
53. Sikkes SA, Knol DL, Pijnenburg YA, de Lange-de Klerk ES, Uitdehaag BM, Scheltens P. Validation of the Amsterdam IADL Questionnaire®, a new tool to measure instrumental activities of daily living in dementia. Neuroepidemiol. 2013;41:35-41.

54. Pfeffer RI, Kurosaki TT, Harrah CHJ, Chance JM, Filos S. Measurement of functional activities in older adults in the community. J Gerontol. 1982;37:323-9.

55. Saykin AJ, Wishart HA, Rabin LA, Santulli RB, Flashman LA, West JD, McHugh $\mathrm{TL}$, Mamourian AC. Older adults with cognitive complaints show brain atrophy similar to that of amnestic MCl. Neurology. 2006;67:834-42.

56. Kaufer DI, Cummings JL, Ketchel P, Smith V, MacMillan A, Shelley T, Lopez OL, DeKosky ST. Validation of the NPI-Q, a brief clinical form of the neuropsychiatric inventory. J Neuropsychiatry Clin Neurosci. 2000;12:233-9.

57. Kaasenbrood F, Hollander M, Rutten FH, Gerhards LJ, Hoes AW, Tieleman RG. Yield of screening for atrial fibrillation in primary care with a hand-held, single-lead electrocardiogram device during influenza vaccination. Europace. 2016;18(10):1514-20.

58. Teunissen CE, Tumani H, Engelborghs S, Mollenhauer B. Biobanking of CSF: international standardization to optimize biomarker development. Clin Biochem. 2014;47(4-5):288-92.

59. Meulenbelt I, Droog S, Trommelen GJ, Boomsma DI, Slagboom PE. Highyield noninvasive human genomic DNA isolation method for genetic studies in geographically dispersed families and populations. Am J Hum Genet. 1995;57(5):1252-4.

60. Ehli EA, Abdellaoui A, Fedko IO, Grieser C, Nohzadeh-Malakshah S, Willemsen G, de Geus EJ, Boomsma DI, Davies GE, Hottenga JJ. A method to customize population-specific arrays for genome-wide association testing. Eur J Hum Genet. 2017;25(2):267-70.

61. Fedko IO, Hottenga JJ, Medina-Gomez C, Pappa I, van Beijsterveldt CE, Ehli EA, Davies GE, Rivadeneira F, Tiemeier H, Swertz MA, et al. Estimation of genetic relationships between individuals across cohorts and platforms: application to childhood height. Behav Genet. 2015;45(5):514-28.

62. Das S, Forer L, Schonherr S, Sidore C, Locke AE, Kwong A, Vrieze SI, Chew EY, Levy S, McGue M, et al. Next-generation genotype imputation service and methods. Nat Genet. 2016;48(10):1284-7.

63. Ghebranious N, Ivacic L, Mallum J, Dokken C. Detection of ApoE E2, E3 and E4 alleles using MALDI-TOF mass spectrometry and the homogeneous mass-extend technology. Nucleic Acids Res. 2005;33(17):e149.

64. van der Lee SJ, Wolters FJ, Ikram MK, Hofman A, Ikram MA, Amin N, van Duijn CM. The effect of APOE and other common genetic variants on the onset of Alzheimer's disease and dementia: a community-based cohort study. Lancet Neurol. 2018;17(5):434-44.

65. Moneta GL, Edwards JM, Chitwood RW, Taylor LMJ, Lee RW, Cummings CA, Porter JM. Correlation of North American Symptomatic Carotid Endarterectomy Trial (NASCET) angiographic definition of 70\% to 99\% internal carotid artery stenosis with duplex scanning. J Vasc Surg. 1993;17: 152-7. discussion 157-159

66. Cardenas VA, Reed B, Chao LL, Chui H, Sanossian N, Decarli CC, Mack W, Kramer J, Hodis HN, Yan M, et al. Associations among vascular risk factors, carotid atherosclerosis, and cortical volume and thickness in older adults. Stroke. 2012;43:2865-70.

67. Wendell CR, Waldstein SR, Ferrucci L, O'Brien RJ, Strait JB, Zonderman AB. Carotid atherosclerosis and prospective risk of dementia. Stroke. 2012;43: 3319-24.

68. van Sloten TT, Schram MT, van den Hurk K, Dekker JM, Nijpels G, Henry RM, Stehouwer CD. Local stiffness of the carotid and femoral artery is associated with incident cardiovascular events and all-cause mortality. J Am College Cardiol. 2014;63:1739-47

69. Fazekas F, Chawluk JB, Alavi A, Hurtig HI, Zimmerman RA. MR signal abnormalities at $1.5 \mathrm{~T}$ in Alzheimer's dementia and normal aging. AJR. 1987; 149:351-6.

70. Scheltens P, Launer LJ, Barkhof F, Weinstein HC, van Gool WA. Visual assessment of medial temporal lobe atrophy on magnetic resonance imaging: interobserver reliability. J Neurol. 1995;242:557-60.

71. Pasquier F, Leys D, Weerts JG, Mounier-Vehier F, Barkhof F, Scheltens P. Inter- and intraobserver reproducibility of cerebral atrophy assessment on MRI scans with hemispheric infarcts. Eur Neurol. 1996;36:268-72.

72. Koedam ELGE, Lehmann M, van der Flier WM, Scheltens P, Pijnenburg YAL, Fox N, Barkhof F, Wattjes MP. Visual assessment of posterior atrophy development of a MRI rating scale. Eur Radiol. 2011;21:2618-25.

73. Curtis C, Gamez JE, Singh U, Sadowsky CH, Villena T, Sabbagh MN, Beach TG, Duara R, Fleisher AS, Frey KA, et al. Phase 3 trial of flutemetamol labeled with radioactive fluorine 18 imaging and neuritic plaque density. JAMA Neurol. 2015;72(3):287-94.

74. Sibomana $\mathrm{M}$, et al. Simultaneous measurement of transmission and emission contamination using a collimated 137Cs point source for the HRRT. In: IEEE Symposium Conference Record Nuclear Science 2004. Rome: IEEE; 2004. https://doi.org/10.1109/NSSMIC.2004.1462795.

75. Sibomana M, et al. New attenuation correction for the HRRT using transmission scatter and total variation regularization. Orlando: IEEE Nuclear Science Symposium Conference Record (NSS/MIC); 2009. https://doi.org/10. 1109/NSSMIC.2009.5401730.

76. Hu ZON, Renisch S, et al. MR-based attenuation correction for a whole-body sequential PET/MR system. In: IEEE Nucl Sci Symp Conference; 2009. p. 3508-12.

77. Healthcare G. EPAR product information-summary of product characteristics. 2014

78. del Campo M, Mollenhauer B, Bertolotto A, Engelborghs S, Hampel H, Simonsen AH, Kapaki E, Kruse N, Le Bastard N, Lehmann S, et al. Recommendations to standardize preanalytical confounding factors in Alzheimer's and Parkinson's disease cerebrospinal fluid biomarkers: an update. Biomark Med. 2012;6(4):419-30.

79. Stam CJ. Use of magnetoencephalography (MEG) to study functional brain networks in neurodegenerative disorders. J Neurol Sci. 2010;289:128-34.

80. de Haan W, van der Flier WM, Koene T, Smits LL, Scheltens P, Stam CJ. Disrupted modular brain dynamics reflect cognitive dysfunction in Alzheimer's disease. Neurolmage. 2012;59:3085-93.

81. Demuru M, Gouw AA, Hillebrand A, Stam CJ, van Dijk BW, Scheltens P, Tijms BM, Konijnenberg $\mathrm{E}$, Ten Kate $\mathrm{M}$, den Braber $\mathrm{A}$, et al. Functional and effective whole brain connectivity using magnetoencephalography to identify monozygotic twin pairs. Sci Rep. 2017;7(1):9685.

82. Mayer MA, Hornegger J, Mardin CY, Tornow RP. Retinal nerve fiber layer segmentation on FD-OCT scans of normal subjects and glaucoma patients. Biomed Opt Express. 2010;1:1358-83.

83. Koronyo Y, Salumbides BC, Black KL, Koronyo-Hamaoui M. Alzheimer's disease in the retina: imaging retinal abeta plaques for early diagnosis and therapy assessment. Neurodegener Dis. 2012;10:285-93.

84. Nandakumar N, Buzney S, Weiter JJ. Lipofuscin and the principles of fundus autofluorescence: a review. Semin Ophthalmol. 2012;27:197-201.

85. Frost $S$, Kanagasingam $Y$, Sohrabi H, Vignarajan J, Bourgeat $P$, Salvado O, Villemagne V, Rowe CC, Macaulay SL, Szoeke C, et al. Retinal vascular biomarkers for early detection and monitoring of Alzheimer's disease. Transl Psychiatry. 2013;3:e233.

86. Minica CC, Dolan CV, Kampert MM, Boomsma DI, Vink JM. Sandwich corrected standard errors in family-based genome-wide association studies. Eur J Hum Genet. 2015;23(3):388-94.

87. Vitaro FBM, Arseneault L. The discordant MZ-twin method: one step closer to the holy grail of causality. Int J Behav Dev. 2009;33(4):376-82.

88. Blokland GA, de Zubicaray Gl, McMahon KL, Wright MJ. Genetic and environmental influences on neuroimaging phenotypes: a meta-analytical perspective on twin imaging studies. Twin Res Hum Genet. 2012;15(3):351-71.

89. Fennema-Notestine C, McEvoy LK, Notestine R, Panizzon MS, Yau WW, Franz CE, Lyons MJ, Eyler LT, Neale MC, Xian H, et al. White matter disease in midlife is heritable, related to hypertension, and shares some genetic influence with systolic blood pressure. Neuroimage Clin. 2016;12:737-45.

Ready to submit your research? Choose BMC and benefit from:

- fast, convenient online submission

- thorough peer review by experienced researchers in your field

- rapid publication on acceptance

- support for research data, including large and complex data types

- gold Open Access which fosters wider collaboration and increased citations

- maximum visibility for your research: over $100 \mathrm{M}$ website views per year

At $\mathrm{BMC}$, research is always in progress.

Learn more biomedcentral.com/submissions 